\title{
Chryseobacterium indologenes peritonitis in a patient with malignant ascites
}

This article was published in the following Dove Press journal:

International Medical Case Reports Journal

19 January 2011

Number of times this article has been viewed

\author{
Yung-Chih Wang' \\ Kuo-Ming Yeh' \\ Sheng-Kang Chiu' \\ Shih-Ta Shang ${ }^{2}$ \\ Li-Ping Kan' \\ Ching-Mei $\mathrm{Yu}^{3}$ \\ Jung-Chung Lin'
}

'Division of Infectious Diseases and Tropical Medicine, Department of Medicine, Tri-Service General Hospital, National Defense Medical Center, Taipei, Taiwan; ${ }^{2}$ Department of Medicine, Taoyuan Armed Forces General Hospital, Taoyuan, Taiwan; ${ }^{3}$ Division of Clinical Pathology, Department of Pathology, Tri-Service General Hospital, National Defense Medical Center, Taipei, Taiwan
Correspondence: Jung-Chung Lin Division of Infectious Diseases and Tropical Medicine, Department of Medicine, Tri-Service General Hospital, National Defense Medical Center, 7F, No. 325, Section 2, Cheng-Kung Road, Neihu II4, Taipei, Taiwan

Tel +886287927257

Fax +886 287927258

Email jclin@ndmctsgh.edu.tw

\begin{abstract}
Chryseobacterium indologenes is an uncommon pathogen of human disease and is usually associated with indwelling devices or immunocompromised hosts. We report here an unusual case of $C$. indologenes peritonitis in an oncological patient with malignant ascites. The patient was treated successfully by trimethoprim-sulfamethoxazole without removal of the catheter.
\end{abstract}

Keywords: Chryseobacterium indologenes, indwelling catheter, peritonitis, trimethoprim-sulfamethoxazole

\section{Introduction}

The use of an indwelling catheter provides an effective method of managing symptomatic ascites. However, the infection rate is especially high, around $11 \%-20 \%$ in patients with malignancy. ${ }^{1}$ Chryseobacterium indologenes, a rare pathogen of humans, is usually associated with indwelling catheter-related infection. ${ }^{2}$ The pathogen is always resistant to most antibiotics but has relatively low virulence. We describe a case of C. indologenes peritonitis in a patient with malignant ascites who received successful treatment without removal of the catheter.

\section{Case report}

A 68-year-old woman who denied having any earlier illness was admitted to our hospital in August 2010 with fever and intermittent abdominal pain for 3 days. She had been diagnosed with adenocarcinoma of the right breast (stage II) in February 2010 and had undergone mastectomy plus adjuvant chemotherapy of paclitaxol (every 21 days). Abdominal distension accompanied with pain developed in July 2010. The abdominal sonographic study showed massive ascites. Malignant ascites was confirmed by the histological result of the ascites taken from the paracentesis. She developed rapid reaccumulation of fluid after repeated paracentesis. An indwelling intraperitoneal catheter had been inserted 2 weeks before this admission. She had not received any antimicrobial agents in the past 3 months because she did not show any sign of infection. Ten days prior to this admission, she underwent the fourth cycle of chemotherapy (paclitaxol $175 \mathrm{mg} / \mathrm{m}^{2}$ ).

On admission, physical examination was remarkable with oral temperature $38.3^{\circ} \mathrm{C}$, blood pressure 126/76 $\mathrm{mm} \mathrm{Hg}$, pulse 94 beats/min, and disclosed diffuse tenderness with rebounding pain over the lower abdomen. The exit site of the drainage catheter showed no erythematous change or pus formation. Cloudy fluid was drained from the indwelling 
catheter. An ultrasound of the abdomen revealed a moderate amount of ascites in the abdominal and pelvic cavities. Laboratory examinations showed hemoglobin $12.7 \mathrm{~g} / \mathrm{dL}$ (normal $12-16 \mathrm{~g} / \mathrm{dL}$ ), white blood cell count $13.7 \times 10^{9}$ per L (normal $4-12 \times 10^{9}$ per L) (88\% neutrophil and $8.9 \%$ lymphocyte), and C-reactive protein $7.5 \mathrm{mg} / \mathrm{L}$ (normal 0-5 mg/L). Ascitic fluid analysis revealed elevated white blood cell count $\left(287.0 \times 10^{6}\right.$ per L) with lymphocyte predominant $(60 \%)$, protein $26.2 \mathrm{~g} / \mathrm{L}$, glucose $7.72 \mathrm{mmol} / \mathrm{L}$, and lactate dehydrogenase $173 \mathrm{U} / \mathrm{L}$. Gram stain of the ascitic fluid obtained from the catheter revealed Gram-negative bacilli. The patient was treated with ampicillin-sulbactam $(1.0 / 0.5$ g every $8 \mathrm{~h})$ intravenously on the first day in the hospital. The blood cultures taken from the peripheral veins did not yield any bacteria. On the sixth day in the hospital, the bacilli were identified as $C$. indologenes. Growth on 5\% sheep blood agar showed smooth, yellow-pigmented colonies (Figure 1). Antimicrobial susceptibility testing showed resistance to most antibiotics including ampicillin-sulbactam, cefazolin, gentamicin, ceftazidime, and ciprofloxacin, but not to trimethoprimsulfamethoxazole. Due to the results, previous therapy was discontinued, and trimethoprim-sulfamethoxazole was initiated intravenously. The patient's condition improved with trimethoprim-sulfamethoxazole treatment after 4 days. We retained the catheter because the patient's condition improved. She received antibiotic treatment for 2 weeks. Cultures of repeated ascites did not yield any bacteria during the following 2 weeks. The patient was discharged without sequelae after 25 days of hospitalization.

\section{Discussion}

Malignant ascites is a well-recognized problem in patients with gastric, pancreatic, colonic, endometrial, ovarian, and breast cancers, lymphoma, and mesothelioma. ${ }^{3}$ They could influence the patient's quality of life significantly. Paracentesis

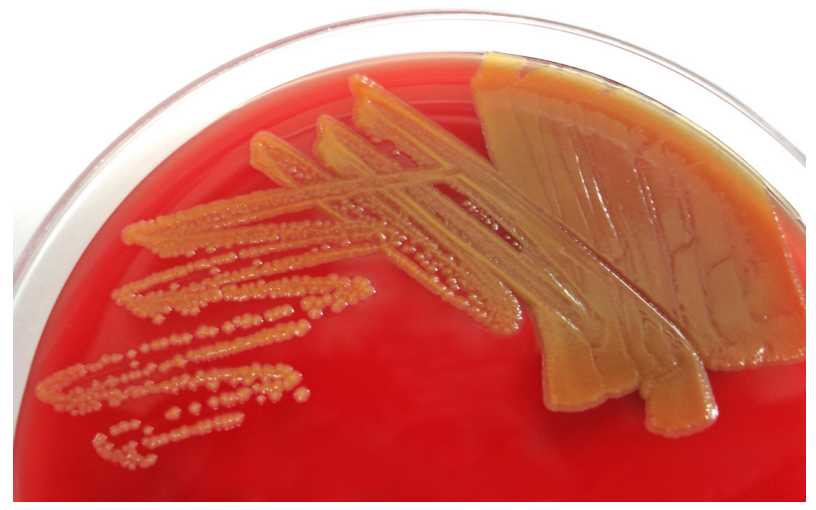

Figure I Colonies of Chryseobacterium indologenes on 5\% sheep blood agar showed yellow pigmentation as a result of flexirubin production. is the most common procedure to relieve symptoms. The indwelling peritoneal catheter has been reported as a safe and effective method for the management of refractory ascites. ${ }^{1,3}$ However, several complications, including peritonitis, leakage, and occlusion, have been documented. ${ }^{1}$ The incidence percentage of peritonitis developed in these patients is from $11 \%$ to $20 \%{ }^{1}$ The median infected time from insertion of indwelling catheter is about 6 weeks, and Acinetobacter baumannii was the most commonly reported pathogen followed by Staphylococcus aureus. ${ }^{1}$

Chryseobacterium species, formerly known as Flavobacterium, are aerobic, oxidase-positive, glucosenonfermenting, Gram-negative rods. Chryseobacteria are not part of the human flora but widely distributed in soil, plants, and water. In the hospital environment, $C$. indologenes is found in water and on wet surfaces of medical tools and equipment. ${ }^{4}$ It was reported that Chryseobacterium species represented only $0.03 \%$ of all bacterial isolates in the SENTRY Antimicrobial Surveillance Program during the period 1997-2001. ${ }^{5}$ The low frequency of infection makes it low in pathogenicity. Some studies also documented that Chryseobacterium species can be cleared rapidly by the immune system. ${ }^{6,7}$

The majority of the infection caused by $C$. indologenes was reported from Taiwan. ${ }^{2,4,8}$ The pathogen can cause a variety of infections, such as pneumonia, pyelonephritis, peritonitis, biliary tract infection, wound infection, and anal abscess. ${ }^{2,8}$ Approximately half of $C$. indologenes infections are associated with indwelling devices that include intravascular catheters, surgical drainage, feeding tubes, endotracheal tubes, and Foley catheters. ${ }^{2}$ Indwelling vascular catheters, feeding tubes, and other medical devices that involve fluid may become reservoirs for Chryseobacterium. ${ }^{8}$ The vast majority of affected hosts were immunocompromised patients affected by malignancies and diabetes mellitus and those exposed to long-term treatment with broad-spectrum antibiotics. ${ }^{3-5}$

The optimal choice of an effective antibiotic for C. indologenes infection is challenging as the organism has a limited spectrum of antimicrobial sensitivity. Resistance to a wide range of antimicrobial agents has been documented: aminoglycosides, penicillins, aztreonam, first-, second-, and third-generation cephalosporins, chloramphenicol, linezolid, and glycopeptides. According to the SENTRY Antimicrobial Surveillance Program, the most effective drugs against $C$. indologenes are the quinolones (levofloxacin, gatifloxacin, garenoxacin, $\geq 95 \%$ susceptibility), trimethoprim-sulfamethoxazole (95\% susceptibility), and piperacillin-tazobactam (90\% susceptibility). ${ }^{7}$ Other 
effective agents are ciprofloxacin, piperacillin, cefepime, ceftazidime, and rifampin (85\% susceptibility). ${ }^{7,9}$ However, removal of the indwelling catheter should be performed if clinical symptoms do not improve after appropriate antibiotic treatment. Hsueh et al suggested that indwelling catheterrelated infection caused by $C$. indologenes may not be a rapid process of deterioration clinically and does not always require removal of the device. ${ }^{2}$ As previously reported, the pathogen exhibits resistance to most common antimicrobial agents. However, the low pathogenicity of this pathogen enables it to be cleared by the immune system. In our case, the patient received appropriate treatment several days after the infection and recovered well. During this time, removal of the catheter may not always be necessary. Appropriate antibiotic treatment is crucial for the management of this infection.

We reported on a patient with breast cancer with malignant ascites who developed $C$. indologenes infection 2 weeks after indwelling catheter insertion. Although the pathogen was resistant to most antibiotics, she was successfully treated with trimethoprim-sulfamethoxazole without removal of the catheter at the end. To the best of our knowledge, this is the first report of $C$. indologenes infection in a patient with an indwelling catheter for malignant ascites. In this case, we concluded that $C$. indologenes, as an important microbe in indwelling catheter-related infections, has high resistance to antibiotics but relatively low virulence in this situation.

\section{Disclosure}

The authors report no conflicts of interest in this work.

\section{References}

1. Lee A, Lau TN, Yeong KY. Indwelling catheters for the management of malignant ascites. Support Care Cancer. 2000;8(6):493-499.

2. Hsueh PR, Teng LJ, Ho SW, Hsieh WC, Luh KT. Clinical and microbiological characteristics of Flavobacterium indologenes infections associated with indwelling devices. J Clin Microbiol. 1996; 34(8):1908-1913.

3. Fleming ND, Alvarez-Secord A, Von Gruenigen V, Miller MJ, Abernethy AP. Indwelling catheters for the management of refractory malignant ascites: a systematic literature overview and retrospective chart review. J Pain Symptom Manage. 2009;38(3):341-349.

4. Hsueh PR, Teng LJ, Yang PC, Ho SW, Hsieh WC, Luh KT. Increasing incidence of nosocomial Chryseobacterium indologenes infections in Taiwan. Eur J Clin Microbiol Infect Dis. 1997;16(8):568-574.

5. Lin JT, Wang WS, Yen CC, et al. Chryseobacterium indologenes bacteremia in a bone marrow transplant recipient with chronic graft-versushost disease. Scand J Infect Dis. 2003;35(11-12):882-883.

6. Towner KJ, Levi K, Vlassiadi M. ARPAC steering group. Genetic diversity of carbapenem-resistant isolates of Acinetobacter baumannii in Europe. Clin Microbiol Infect. 2008;14(2):161-167.

7. Kirby JT, Sader HS, Walsh TR, Jones RN. Antimicrobial susceptibility and epidemiology of a worldwide collection of Chryseobacterium spp: report from the SENTRY Antimicrobial Surveillance Program (1997-2001). J Clin Microbiol. 2004;42(1):445-448.

8. Hsueh PR, Hsiue TR, Wu JJ, et al. Flavobacterium indologenes bacteremia: clinical and microbiological characteristics. Clin Infect Dis. 1996;23(3):550-555.

9. Chang JC, Hsueh PR, Wu JJ, Ho SW, Hsieh WC, Luh KT. Antimicrobial susceptibility of flavobacteria as determined by agar dilution and disk diffusion methods. Antimicrob Agents Chemother. 1997; 41(6):1301-1306.
International Medical Case Reports Journal

\section{Publish your work in this journal}

The International Medical Case Reports Journal is an international, peer-reviewed open-access journal publishing original case reports from all medical specialties. Previously unpublished medical posters are also accepted relating to any area of clinical or preclinical science. Submissions should not normally exceed 2,000 words or

\section{Dovepress}

4 published pages including figures, diagrams and references. The manuscript management system is completely online and includes a very quick and fair peer-review system, which is all easy to use. Visit $\mathrm{http} / / / \mathrm{www}$.dovepress.com/testimonials.php to read real quotes from published authors. 